Research Journal of Applied Sciences 13 (4): 235-240, 2018

ISSN: $1815-932 \mathrm{X}$

(C) Medwell Journals, 2018

\title{
Real-Time Signal Coverage and Quality Monitoring Towards Performance Optimisation in Contemporary Mobile Broadband Cellular Networks
}

\author{
Joseph Isabona and Viranjay M. Srivastava \\ Department of Electronic Engineering, Howard College, University of KwaZulu-Natal, \\ 4041 Durban, South Africa
}

\begin{abstract}
A proactive service quality monitoring by means of advanced expert-driven field test analysis is of utmost importance for performance optimisation in contemporary operating wireless cellular communication networks. This monitoring requirement is particularly emphasized in mobile broadband-based networks such as HSPA due to inherent high-interference and network dynamism with multiple sources of uncertainties such as multipath radio wave propagation channel conditions which directly influence the data transmission quality. In this research, modern experimental equipment has been explored to critically investigate the performance of live HSPA commercial networks using significant signal coverage and Quality of Service (QoS) parameters at radio link and network levels. By using Radio Frequency failure $(\mathrm{RF})$ detection matrix and drill down analysis on collected drive test data, the network coverage and quality problems has been identified. The impact of dynamically changing network condition on the end user experience which are indicated by specific channel signal quality and data rate metrics are also graphically presented. The research is concluded with splendid steps and recommendations on how to improve the overall performance of the HSPA and the effective deployment of future networks in the studied locations.
\end{abstract}

Key words: HSPA, real-time measurement, broadband radio networks, $R F$ failure detection, link quality, bit error rate

\section{INTRODUCTION}

Over the last decade, the public mobile wireless communications have undergo remarkable growth in terms of evolution, deployment and mobile subscription, since, the emergence of second generation system networks such as GSM in the early 90's to the present-day mobile broadband networks such UMTS, HSPA and LTE. According Ericson Mobility report (Anonymous, 2016), the total global mobile subscriptions stood at 7.3 billion in the third quarter alone, 2015. As highlighted in the report, India grew the most in terms of net additions during the quarter +13 million, followed by China +7 million, the US +6 million, Myanmar +5 million and Nigeria +4 million.

As the different wireless cellular network system communications standards continuous to evolve, accompanied with paralleled continuous increase mobile user service subscription, one key area that cannot be ignore is the Quality of Service (QoS) the end-user experiences from one location to another. Often time, radio signals and data rate transmission quality in wireless cellular communication network's environment are impacted by different limiting factors. For example, in terrains with uneven morphology (e.g., built-up area), the signal coverage and quality is affected by a lots blockades such as human structures, non-uniform human/vehicular traffic, hills, vegetation and the like. For this reason, there is a strong need for a systematic real-time individual assessment of deployed commercial mobile communication networks. This is to evaluate their robustness and performance capability in different radio propagation scenarios. It will also provide a platform to identify problems, resolve them and reconfigure the networks for optimal performance.

This research deals with a systematic performance assessment of HSPA network, considering the radio coverage, service quality and link reliability performance trends in typical suburban environments. This is an extension of previous on UMTS networks in a campus environment (Isabona, 2013). A closely related approach have been adopted by Alghamdi and Kostanic (2010) and Agboje et al. (2016) but for WiMAX and GSM networks.

Corresponding Author: Joseph Isabona, Department of Electronic Engineering, Howard College, University of KwaZulu-Natal, 4041 Durban, South Africa 


\section{MATERIALS AND METHODS}

In academic literature, many testing methods are present for measuring and monitoring the performance of service quality performance in cellular wireless networks. The two most central ones are: controlled drive testing (Isabona, 2013; Alghamdi and Kostanic, 2010; Agboje et al., 2016; Isabona and Konyeha, 2013) and crowd-sourced testing (Messina et al., 2013). While the formal is a form of mobile data acquisition method using sophisticated testing equipment that is connected to mobile devices and housed in vehicles for adept drive testing; the latter involves the use of mobile applications and consumers devices to obtain relevant network data. In this research, the drive-test system procedure was used for data collection.

Measurement campaign: Measurements were performed along the test area using the drive-test investigation procedure specified by Ascon (Anonymous, 2010) as shown in Fig. 1. The drive-test tools consisted of two Ericson TEMS mobiles of W995 (i.e., the User Equipment (UE)) Model, Ericsson TEMS drive test software-equipped laptop, scanner and GPS all housed in a rover car containing the compass and GPS receiver. The GPS receiver is for tracking the exact location of each test point. The scanner measures all used carriers/cells and their corresponding downlink scrambling codes. The TEMS test software-equipped laptop with the two mobiles is used to measure node B performance over the air and display the obtain data along the drive test routes. The test was conducted in a commercial HSPA mobile network implemented on the $2100 \mathrm{MHz}$ band. The drive test routes were chosen in modus with good engineering practices associated with network performance monitoring and optimisation. This enabled us to capture the full networks cell coverage and quality of service parameters in form of $\log$ files before handover. The test area is covered by 3 cell sites. The test environment was typical Suburban

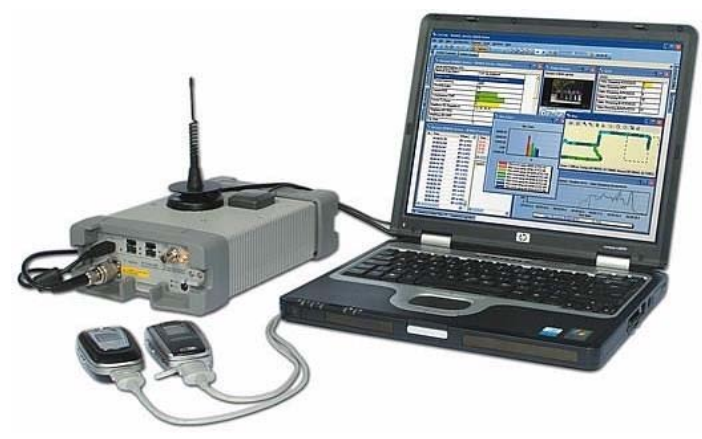

Fig. 1: Typical drive test investigation tools and set-up with a mix of living areas, commercial areas and an open areas. For post processing of test log data, MapInfo, MATLAB and Microsoft Excel were used.

\section{RESULTS AND DISCUSSION}

For presentation of results, the following Performance Indicators (KPI's) have been considered (Tanjo and Lipovac, 2013; Isabona and Ekpenyong, 2008; Isabona and Ekpenyong, 2009):

- $\quad$ RSCP (Received Signal Code Power)

- Ec/No (received Energy per chip divided by the power density in the band)

- BLER (Block-Error Rate)

RSCP: It is the signal strength measured in the unit of $\mathrm{dBm}$. It is used as an indicator for signal coverage assessment and for calculating path loss. According to the requirements on radio frequency optimization, the value of $\mathrm{Ec} / \mathrm{No}$ must be $=-85 \mathrm{~dB} \mathrm{~m}$ or higher in $98 \%$ of coverage area for standard usage. RSCP is related to path loss by:

$$
\operatorname{RSCP}(\mathrm{dBm})=\mathrm{P}_{\mathrm{TX}} \text {-pathloss }
$$

$$
\text { Path loss }=\mathrm{A} / \mathrm{r}^{-\mathrm{n}}
$$

Where:

$\mathrm{P}_{\mathrm{TX}}=$ The node $\mathrm{B}$ transmit Power

$\mathrm{A}=\mathrm{A}$ constants and its value depends on node $\mathrm{B}$ Antenna parameters

$\mathrm{r} \quad=$ Distance between node $\mathrm{B}$ and UE

$\mathrm{n}$ = Propagation path loss exponent and it is also an environment dependent parameter

$\mathbf{E c} /$ No: It is the level of interference plus the noise level with regard to the pilot control channel in the band. For an acceptable coverage quality/interference level, the value of $\mathrm{Ec} / \mathrm{No}$ must be $=-9 \mathrm{~dB}$ or higher in $95 \%$ of coverage area at the User Equipment (UE) terminal as indicated in Table 1-2. Thus, higher Ec/No implies the better signal quality or low interference level.

BLER: is an important indicator for performance assessment of link connection quality and integrity. It expresses the level of transmission errors on the radio interface. Specifically, it is defined as the ratio of the number of erroneous blocks received over the total number of blocks transmitted. The higher the BLER, the more packet retransmissions which in turn will lead long delay and poor power efficiency. Practically, the value of BLER should be $=0.1$ (i.e., $10 \%$ ) must or higher in $95 \%$ of coverage area in the downlink direction. 
The probability distribution function (pdf) plots of RSCP coverage for site A are presented in Fig. 2-4. From the pdf analysis, 100,85 and $95 \%$ of RSCP measured values are better than $-85 \mathrm{dBm}$ acceptable quality performance threshold in sectors 1-3. Also, for coverage quality, the pdf analysis in Figs 5-7, shows that 95, 82 and $95 \%$ of Ec/No measured values are better than $-85 \mathrm{dBm}$ acceptable quality performance threshold in sector 1-3. Specially, we also infer from the pdf plots that it is only the measured RSCP values from sector 1 , out of the three sectors in site A that follows Gaussian distribution. This agrees with the results from our previous research by Isabona and Konyeha (2013) that the received signal values does not always follow the Gaussian distribution. A similar observation have also been made in another research by (Robitzsch and Murphy, 2012).

Table 1: Radio coverage and quality problem detection matrix (Sanchez-Gonzales, 2008)

\begin{tabular}{|c|c|}
\hline Criteria/Coverages & Sectors \\
\hline \multicolumn{2}{|l|}{ Low RSCP } \\
\hline Low Ec/No & $\begin{array}{l}\text { Non-dominant server area/uplink and downlink } \\
\text { coverage problems }\end{array}$ \\
\hline High Ec/No & $\begin{array}{l}\text { Downlink coverage problems (i.e., poor downlink } \\
\text { coverage) }\end{array}$ \\
\hline \multicolumn{2}{|l|}{ High RSCP } \\
\hline Low Ec/No & $\begin{array}{l}\text { High downlink interference and pilot pollution } \\
\text { problems }\end{array}$ \\
\hline$\underline{\text { High RSCP }}$ & Uplink interference \\
\hline \multicolumn{2}{|c|}{$\begin{array}{l}\text { Table 2: Radio coverage and quality evaluation criteria (Anonymous, 2006; } \\
\text { Isabona and Ojuh, 2014) }\end{array}$} \\
\hline Indicators & KPI target \\
\hline Coverage & $>-88 \mathrm{~dB} m$ over $98 \%$ of coverage area \\
\hline Quality & $>-9 \mathrm{~dB}$ over $99 \%$ of area \\
\hline Reliability & $>0.1$ over $95 \%$ of coverage area \\
\hline
\end{tabular}

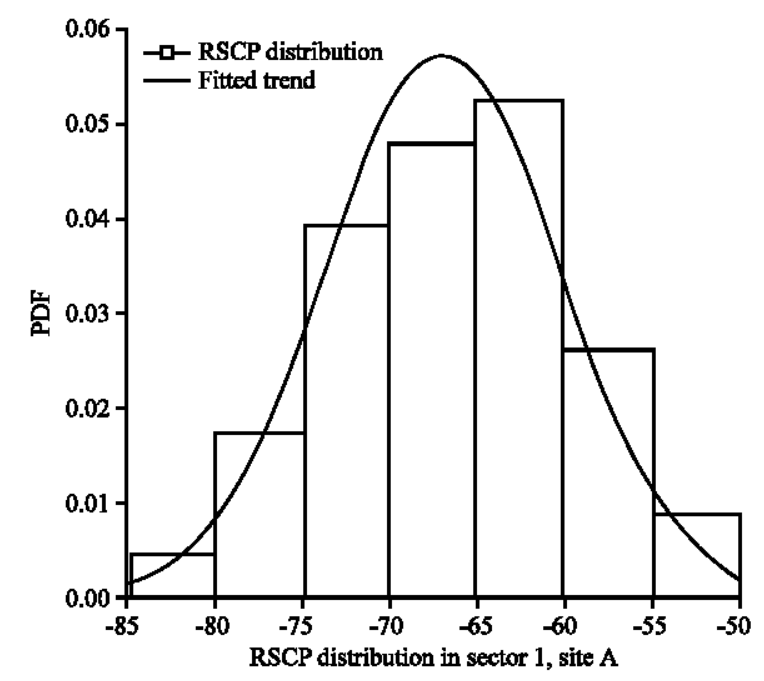

Fig. 2: Measured RSCP distribution in sector 1, site A

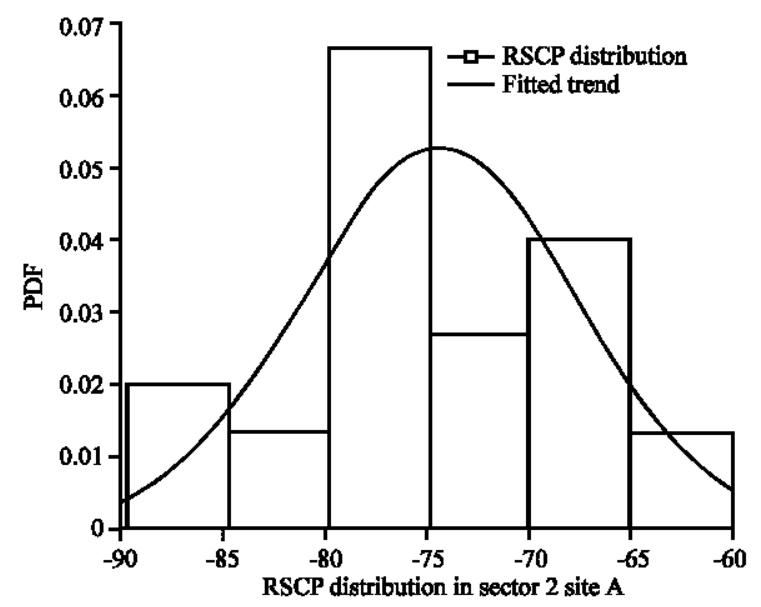

Fig. 3: Measured RSCP distribution in sector 2, site A

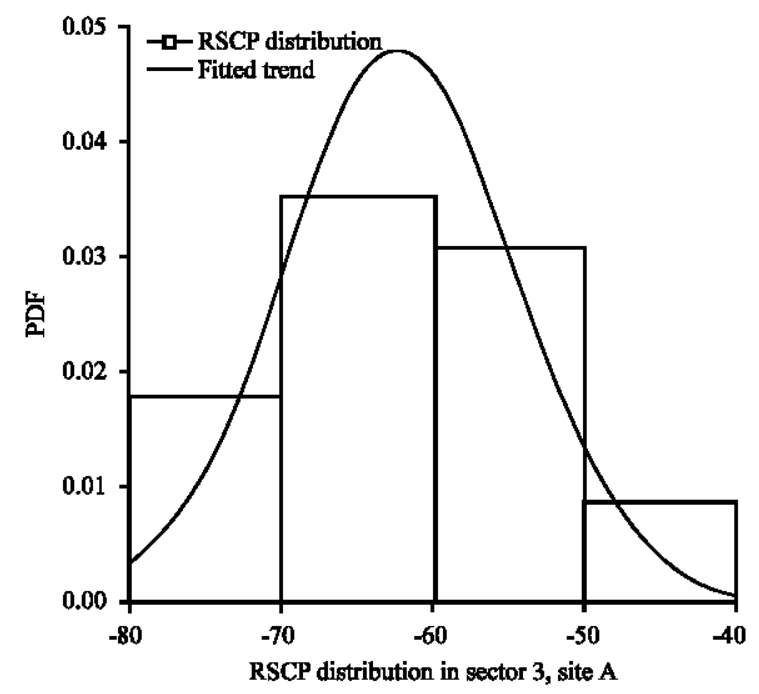

Fig. 4: Measured RSCP distribution in sector 3, site A

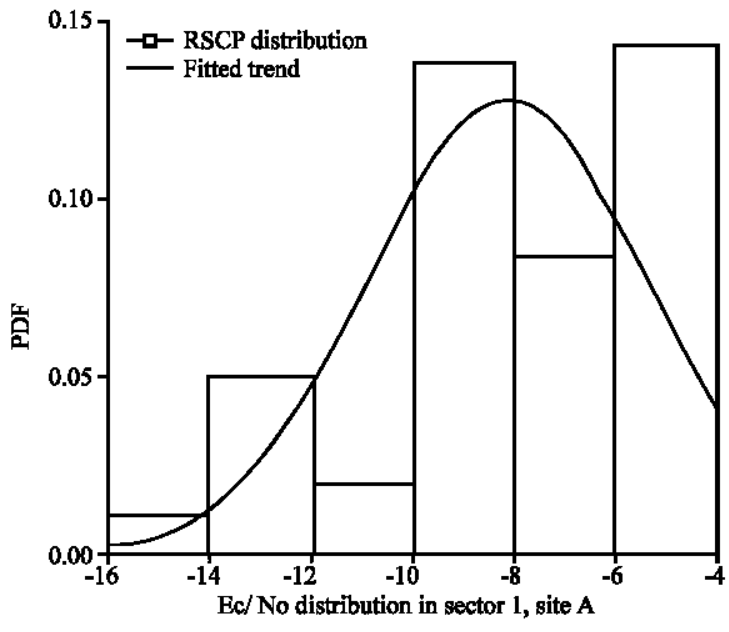

Fig. 5: Measured Ec/No distribution in sector 1, site A 
Res. J. Applied Sci., 13 (4): 235-240, 2018

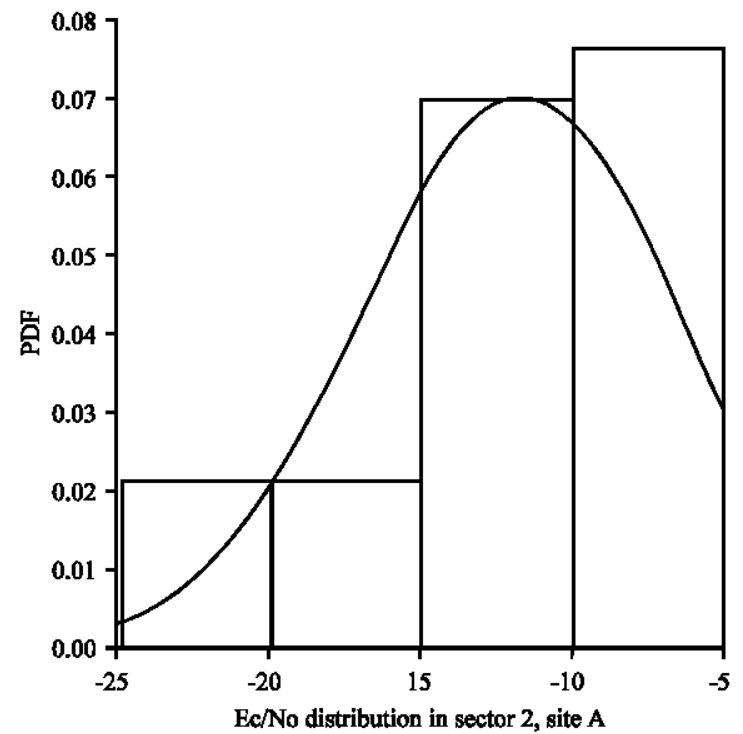

Fig. 6: Measured Ec/No distribution in sector 2, site A

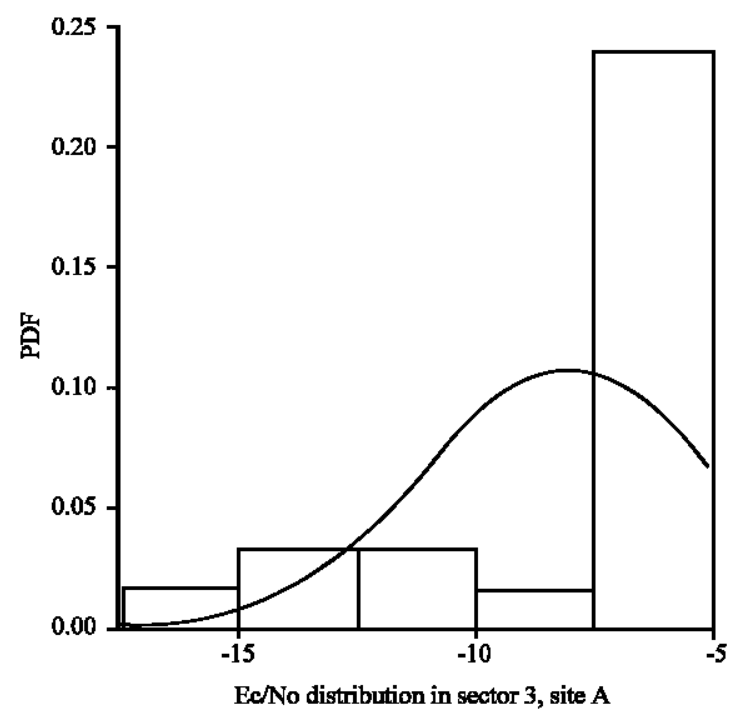

Fig. 7: Measured Ec/No distribution in sector 3, site A

Table 3-6 display the summary of statistical analysis of measured signal coverage and link quality performance parameters in sites A-C.

Presented in Fig. 8-10 are plots to examine the impact of radio coverage and quality on BLER performance for site A. Using the thresholds: BLER $\leq 0.1$, it is observed that 90,98 and $91 \%$ of RSCP and Ec/No measured values are providing good link quality in site A. Similar performance was also observed in sites $\mathrm{B}$ and $\mathrm{C}$ but we couldn't show the results due to space constraint. However, the results summary obtained based on statistical analysis for all the three sites are shown in
Table 3: Measured values of RSCP Ec/No and BLER in site A, urban

\begin{tabular}{lrrr}
\hline KPI/Values & Sector 1 & Sector 2 & Sector 3 \\
\hline RSCP & & & \\
Mean & -66.880 & -74.550 & -62.470 \\
Minimum & -84.000 & -87.000 & -76.000 \\
Maximum & -52.000 & -62.000 & -47.000 \\
Median & -66.500 & -76.000 & -61.000 \\
SD & 6.940 & 6.810 & 7.680 \\
Ec/No & & & \\
Mean & -8.150 & -11.750 & -6.610 \\
Minimum & -15.000 & -22.000 & -16.000 \\
Maximum & -4.000 & -5.000 & -3.000 \\
Median & -8.250 & -12.000 & -5.500 \\
SD & 2.805 & 5.320 & 3.720 \\
BLER & & & \\
Mean & 0.090 & 0.105 & 0.080 \\
Minimum & 0.070 & 0.070 & 0.070 \\
Maximum & 0.110 & 0.180 & 0.120 \\
Median & 0.080 & 0.090 & 0.070 \\
SD & 0.011 & 0.032 & 0.014 \\
\hline & & &
\end{tabular}

Table 4: Measured values of RSCP, Ec/No and BLER in site B, Suburban

\begin{tabular}{lrrr}
\hline KPI/Values & Sector 1 & Sector 2 & Sector 3 \\
\hline RSCP & & & \\
Mean & -76.890 & -68.69 & -75.260 \\
Minimum & -87.000 & -77.00 & -87.000 \\
Maximum & -68.000 & -59.00 & -58.000 \\
Median & -75.000 & -69.00 & -80.000 \\
SD & 6.480 & 5.59 & 9.740 \\
Ec/No & & & \\
Mean & -6.250 & -7.73 & -9.470 \\
Minimum & -13.500 & -24.00 & -19.000 \\
Maximum & -4.500 & -3.50 & -5.000 \\
Median & -6.000 & -4.00 & -9.000 \\
SD & 1.502 & 7.07 & 3.820 \\
BLER & & & \\
Mean & 0.077 & 0.098 & 0.091 \\
Minimum & 0.070 & 0.070 & 0.070 \\
Maximum & 0.110 & 0.330 & 0.140 \\
Median & 0.077 & 0.071 & 0.087 \\
SD & 0.005 & 0.064 & 0.017 \\
\hline
\end{tabular}

Table 5: Measured values of RSCP, Ec/No and BLER in site B, rural

\begin{tabular}{lrrr}
\hline KPI/Values & Sector 1 & Sector 2 & Sector 3 \\
RSCP & & & \\
Mean & -65.840 & -70.3100 & -64.500 \\
Minimum & -85.000 & -84.0000 & -76.000 \\
Maximum & -49.000 & -55.0000 & -52.000 \\
Median & -64.000 & -70.0000 & -65.000 \\
SD & 9.720 & 8.8100 & 6.760 \\
Ec/No & & & \\
Mean & -7.400 & -9.5500 & -8.040 \\
Minimum & -19.000 & -15.0000 & -16.500 \\
Maximum & -3.500 & -4.0000 & -4.000 \\
Median & -5.500 & -9.5000 & -8.250 \\
SD & 3.750 & 3.2100 & 3.160 \\
BLER & & & \\
Mean & 0.083 & 0.0900 & 0.085 \\
Minimum & 0.070 & 0.0700 & 0.070 \\
Maximum & 0.140 & 0.1100 & 0.120 \\
Median & 0.075 & 0.0889 & 0.084 \\
SD & 0.015 & 0.0130 & 0.013 \\
\hline
\end{tabular}

Table 6 the best BLER performance was achieved in sites $\mathrm{A}, \mathrm{B}$ and $\mathrm{C}$ with $\mathrm{Ec} / \mathrm{No}$ and RSCP between -4 to $-6 \mathrm{~dB}$ and -50 to $-70 \mathrm{dBm}$, respectively. 
Table 6: Achieved coverage, quality and link reliability performance in

\begin{tabular}{|c|c|c|c|}
\hline Variables & Sector 1 & Sector 2 & Sector 3 \\
\hline \multicolumn{4}{|l|}{ Site A } \\
\hline RSCP target & \multicolumn{3}{|c|}{$\mathrm{RSCP} \geq-88 \mathrm{dBm}$ over $98 \%$ coverage area } \\
\hline Achieve & 100 & 85 & 100 \\
\hline Ec/No target & \multicolumn{3}{|c|}{$\mathrm{Ec} / \mathrm{No} \geq-9 \mathrm{~dB}$ over $95 \%$ coverage area } \\
\hline Achieved & 95 & 82 & 95 \\
\hline BLER target & \multicolumn{3}{|c|}{$\mathrm{BLER} \geq 0.1(10 \%)$} \\
\hline Achieve & 98 & 83 & 98 \\
\hline \multicolumn{4}{|l|}{ Site B } \\
\hline RSCP target & \multicolumn{3}{|c|}{$\mathrm{RSCP} \geq-88 \mathrm{dBm}$ over $98 \%$ coverage area } \\
\hline Achieve & 84 & 100 & 90 \\
\hline $\mathrm{Ec} /$ No target & \multicolumn{3}{|c|}{$\mathrm{Ec} / \mathrm{No} \geq-9 \mathrm{~dB}$ over $95 \%$ coverage area } \\
\hline Achieved & 97 & 91 & 79 \\
\hline BLER target & \multicolumn{3}{|c|}{$\mathrm{BLER} \geq 0.1(10 \%)$} \\
\hline Achieve & 91 & 96 & 85 \\
\hline \multicolumn{4}{|l|}{ Site C } \\
\hline RSCP target & \multicolumn{3}{|c|}{$\mathrm{RSCP} \geq-88 \mathrm{~dB}$ m over $98 \%$ coverage area } \\
\hline Achieve & 97 & 100 & 100 \\
\hline Ec/No target & \multicolumn{3}{|c|}{$\mathrm{Ec} / \mathrm{No} \geq-9 \mathrm{~dB}$ over $95 \%$ coverage area } \\
\hline Achieved & 97 & 92 & 95 \\
\hline BLER target & \multicolumn{3}{|c|}{$\mathrm{BLER} \geq 0.1(10 \%)$} \\
\hline Achieve & 97 & 96 & 94 \\
\hline
\end{tabular}

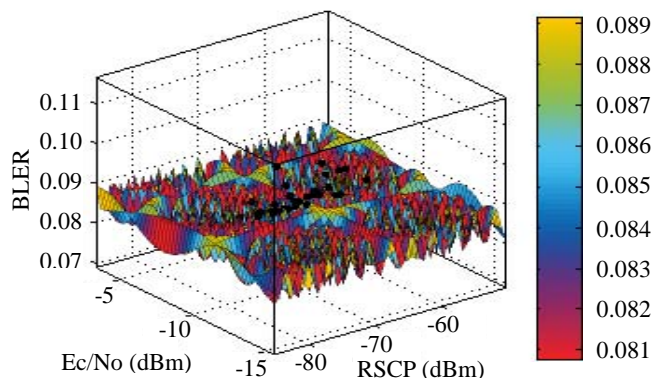

Fig. 8: BLER performance trend with Ec/No and RSCP in sector 1 , site $\mathrm{A}$

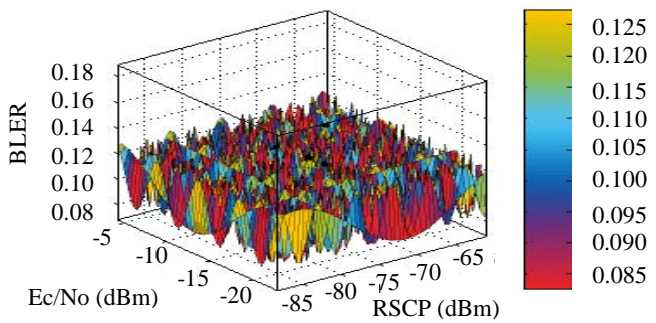

Fig. 9: BLER performance trend with $\mathrm{Ec} / \mathrm{No}$ and RSCP in sector 2 , site $\mathrm{A}$

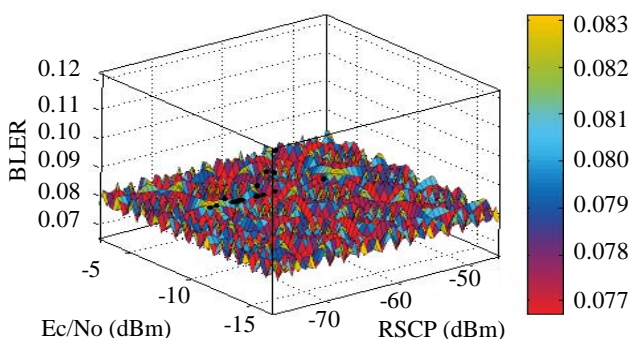

Fig. 10: BLER performance trend with Ec/No and RSCP in sector 2 , site A
In site $\mathrm{A}$, a good number of low RSCP values but with high EC/No quality were found at different measurement locations, especially in sectors 1 and 2 . As clearly seen in Table 6 , the two sectors recorded as low -89 and $-90 \mathrm{~dB} \mathrm{~m}$ Ec/No mean values, both which are lower than $-85 \mathrm{~dB}$ accepted coverage threshold at the UE terminal. This indicate poor coverage area. In sites $\mathrm{A}$ and $\mathrm{B}$, a reverse performance is the case as many measurement locations recorded high RSCP values but with low EC/No quality. This an indication of high interference problems. On the other hand, many measurement points in sector 1 of site $\mathrm{B}$ and sector 2 of site $\mathrm{C}$ recorded both low RSCP and $\mathrm{EC} / \mathrm{No}$, thus, showing the two sectors uplink and downlink interference limited. Increase in interference is also an indication of increase traffic in the area.

\section{CONCLUSION}

To proficiently ensure a good service quality for both individual and commercial subscribers as well maximise the impact of network investment, mobile service operators need an up-to-date view of their deployed network performance capacities and limitations in different propagation scenarios. This information in strongly needed in today's competitive telecom market to further reconfigure the network for better performance. In this research, modern experimental equipment has been explored to critically study the performance of live HSPA commercial networks with focus on signal coverage, quality and capacity metrics. By using Radio Frequency failure (RF) detection matrix and drill down analysis on collected drive test data, the network coverage and quality problems has been identified. The impact of dynamically changing network condition on the end user experience have are also graphically presented, using specific channel signal quality and error rate metrics. The results could form the basis for performance optimisation of mobile cellular networks.

\section{RECOMMENDATIONS}

In view of the results presented in this research, the following recommendations are made to enhance the performance of HSPA networks in the study area: for uplink and downlink coverage areas (i.e., areas with low RSCP and Ec/No), the antenna azimuths should be tuned to create one dominant pilot. For poor downlink coverage areas (i.e., areas with low RSCP but high Ec/No), the antenna azimuths should also be adjusted but this time towards the coverage gaps and blind spots. For high downlink interference areas (i.e., areas with high RSCP but low Ec/No), decrease CPICH of interfering cell and the 
antenna should be downtilted in correspondence to the scrambling codes involved. There is need to increase the cell size or coverage range of each site via. sector addition or site addition.

\section{REFERENCES}

Agboje, O.E., A.E. Tbhaze and O.B. Idowu-Bismark, 2016. Performance analysis of wireless mobile network. Intl. J. Appl. Eng. Res., 11: 6058-6062.

Alghamdi, F.A. and I. Kostanic, 2010. Methodology for WiMax performance optimisation using drive test data. Proceedings of the 8th International Conference on Computing Communications and Control Technologies (CCCT'10), April 6-9, 2010, DoubleTree by Hilton Orlando at SeaWorld, Orlando, Florida, USA., pp: 1-6.

Anonymous, 2006. WCDMA network planning and optimisation, 80-W0853-1 Review B. Qualcomm, San Diego, California.

Anonymous, 2010. TEMS investigation, drive test tools for mobile networks. ASCON, Saint Petersburg, Russia.

Anonymous, 2016. Ericson mobility report. Ericsson, Stockholm, Sweden.

Isabona, J. and C.C. Konyeha, 2013. Experimental study of UMTS radio signal propagation characteristics by field measurement. Am. J. Eng. Res., 2: 99-106.

Isabona, J. and D.O. Ojuh, 2014. Radio link quality measurement survey over HSDPA radio interface: A holistic technique for efficient networks performance monitoring in wireless communication systems. Niger. J. Phys., 25: 46-54.

Isabona, J. and M. Ekpenyong, 2008. On throughput estimation of CDMA unslotted ALOHA system for random access networks. Res. J. Applied Sci., 3: $560-565$.

Isabona, J. and M.E. Ekpenyong, 2009. Probabilistic link reliability model for wireless communication networks. Int. J. Signal Syst. Control Eng. Appl., 2: 22-29.
Isabona, J., 2013. Real time monitoring of service quality of a deployed UMTS wireless networks in campus environment-an optimisation perspective. Intl. J. Inf. Sci. Intell. Syst., 2: 1-16.

Messina, A., G. Caragea, P.T. Compta, F.H. Fitzek and S.A. Rein, 2013. Investigating call drops with field measurements on commercial mobile phones. Proceedings of the 2013 IEEE 77th Conference on Vehicular Technology (VTC'13), June 2-5, 2013, IEEE, Dresden, Germany, ISBN:978-1-4673-6337-2, pp: $1-5$.

Robitzsch, S. and L. Murphy, 2012. Empirical analysis of measured 802.11 receive signal strength values using various atheros based mini-PCI cards. Proceedings of the 2012 IEEE International Symposium on World of Wireless, Mobile and Multimedia Networks (WoWMoM'12), June 25-28, 2012, IEEE, San Francisco, California, ISBN:978-1-4673-1238-7, pp: 1-6.

Sanchez-Gonzalez, J., O. Sallent, J. Perez-Romero, R. Agusti and M.A. Diaz-Guerra et al., 2008. A new methodology for RF failure detection in UMTS networks. Proceedings of the Symposium on Network Operations and Management (NOMS'08), April 7-11, 2008, IEEE, Salvador, Brazil, ISBN: 978-1-4244-2065-0, pp: 718-721.

Tanjo, A. and V. Lipovac, 2013. Practical performance of UMTS-HSPA networks in high buildings. Proceedings of the 2nd WSEAS International Conference on Circuits, Systems, Communications, Computers and Applications, June 25-27, 2013, WSEAS, Heraklion, Greece,ISBN:978-960-474-308-7, pp: 171-176.

Zamudio-Castro, I., S. Vidal-Beltran, J. Ponce-Rojas and J. Sosa-Pedroza, 2011. Experimental analysis of a node $\mathrm{B}$ coverage based on the $\mathrm{CPICH}$ and Ec/Io values. Wirel. Eng. Technol., 2: 23-29. 